\section{Case Report}

Korean J Transplant 2020;34:121-125

https://doi.org/10.4285/kjt.2020.34.2.121

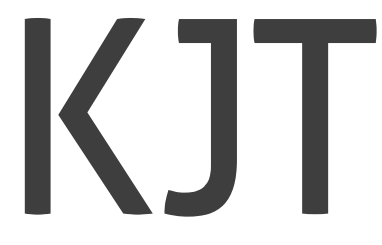

pISSN 2671-8790

elSSN 2671-8804

\title{
A case of successful late steroid withdrawal after $\mathrm{ABO}$-incompatible kidney transplantation
}

\author{
Jeong Min Cho ${ }^{1}$, Heungman Jun ${ }^{2}$, Hyung Ah Jo ${ }^{1}$, Kum Hyun Han' ${ }^{1}$ Han-Seong Kim ${ }^{3}$, \\ Sang Youb $\mathrm{Han}^{1}$ \\ 'Department of Internal Medicine, Inje University College of Medicine, Ilsan Paik Hospital, Goyang, Korea
2Department of Surgery, Inje University College of Medicine, Ilsan Paik Hospital, Goyang, Korea
${ }^{3}$ Department of Pathology, Inje University College of Medicine, Ilsan Paik Hospital, Goyang, Korea
}

Few data exist regarding steroid withdrawal in $\mathrm{ABO}$-incompatible (ABO-i) kidney transplantation (KT). Here, we report a case of steroid withdrawal after ABO-i KT. A 46-year-old man diagnosed with Henoch-Schonlein purpura received ABO-i KT from his 42-year-old sister. The recipient and donor blood types were $O$ and $A B$, respectively. His preoperative $A B O$ antibody titers were anti- $A$ of $1: 16$ and anti- $B$ of $1: 8$ in isoagglutinin test. HLA mismatch was 0 and he received a single $325 \mathrm{mg} / \mathrm{m}^{2}$ dose of intravenous (IV) rituximab 4 weeks before KT. Three sessions of plasma exchange were undertaken before KT and low-dose IV immunoglobulin of $0.1 \mathrm{~g} / \mathrm{kg}$ was administered after plasma exchange. On the day of the operation, $\mathrm{ABO}$ antibody titer decreased to anti-A of 1:4 and anti-B of 1:2. Renal function remained stable after KT. The patient wished to stop steroid treatment despite the risk of rejection after withdrawal. Steroid tapering was initiated at 20 months and accomplished at 26 months after KT. At that time, serum creatinine level was $1.13 \mathrm{mg} / \mathrm{dL}$, and anti-A and anti-B titers were $1: 8$ and 1:2, respectively. No issues were observed after steroid withdrawal. At 48 months after $\mathrm{KT}$, serum creatinine level was $1.21 \mathrm{mg} / \mathrm{dL}$, and anti-A and anti-B antibody titers were $1: 32$ and 1:2, respectively. Steroid withdrawal in ABO-i KT might be considered in immunologically low-risk

Keywords: Kidney transplantation; ABO blood-group system; Blood group incompatibility; Steroid; Withholding treatment patients. This is an Open Access article distributed under the terms of the Creative Commons Attribution Non-Commercial License (http://creativecommons.org/licenses/ by-nc/4.0/) which permits unrestricted non-commercial use, distribution, and reproduction in any medium, provided the original work is properly cited.
(C) The Korean Society for Transplantation

Revised June 4, 2020

Corresponding author: Sang Youb Ha University Ilsan Paik Hospital, 170 Korea

Fax: +82-31-910-7219

E-mail: hansy@paik.ac.kr

\section{INTRODUCTION}

Steroid withdrawal after $\mathrm{ABO}$-compatible (ABO-c) kidney transplantation (KT) has been attempted to minimize long-term negative effects of steroid treatment. Recently, $\mathrm{ABO}$-incompatible (ABO-i) KT has started to be applied across worldwide. However, limited data existing regarding steroid withdrawal after ABO-i KT show a higher rejection rate, from $7 \%$ to $55 \%[1-4]$. These differences may have been affected by the differences in immunosuppressive regimen and/or time of steroid withdrawal, and presence or absence of protocol biopsy. Here, we report the case of a patient who stopped steroids treatment 26 months after $\mathrm{KT}$ and has maintained stable renal function for 48 months. To the best of our knowledge, this is the first case reported in Korea featuring late steroid withdrawal with no issue of acute or chronic rejection. 


\section{HIGHLIGHTS}

- Few data exist regarding early steroid withdrawal in $\mathrm{ABO}$-incompatible (ABO-i) kidney transplantation (KT) cases.

- Steroid withdrawal in ABO-i KT might be considered in immunologically low-risk patients.

\section{CASE REPORT}

A 46-year-old man had received an ABO-i KT from his 42-yearold sister. He had been diagnosed with Henoch-Schonlein purpura 16 years previously. He had undergone hemodialysis for 5 months. His blood type was 0 , and his sister's type was $A B$. His preoperative $A B O$ antibody titer was anti-A of 1:16 and anti-B of 1:8 in isoagglutinin test. HLA mismatch was 0 . Complement-dependent cytotoxic crossmatch tests of $\mathrm{T}$ and $B$ cells and flow-cytometric crossmatch test of $T$ cell were negative. Panel-reactive antibody (PRA) was negative for classes I and II.

He received a single $325 \mathrm{mg} / \mathrm{m}^{2}$ dose of intravenous (IV) rituximab 4 weeks before KT. Three sessions of plasma exchange were undertaken before KT, and low-dose $0.1 \mathrm{~g} / \mathrm{kg} \mathrm{IV} \mathrm{immunoglobulin} \mathrm{was} \mathrm{administered} \mathrm{after} \mathrm{plas-}$ ma exchange. On the day of the operation, $A B O$ antibody titer decreased to anti-A of 1:4 and anti-B of $1: 2$ in isoagglutinin test. Oral prednisolone $20 \mathrm{mg}$ once per day was initiated 3 days before KT. On the day of the operation, IV methylprednisolone $500 \mathrm{mg}$ was administered, with daily reductions thereafter. Tacrolimus $1.5 \mathrm{mg}$ and mycophenolate mofetil (MMF) $750 \mathrm{mg}$ (both twice per day) were initiated 3 days before KT and continued thereafter. As induction therapy, IV basiliximab $20 \mathrm{mg}$ was administered on the day of KT and after 4 days.
Following $\mathrm{KT}$, serum creatinine level gradually decreased. By postoperative day 5 , serum creatinine and blood urea nitrogen levels had decreased to 1.06 and $15.5 \mathrm{mg} / \mathrm{dL}$, respectively. Kidney Doppler the day after KT showed normal perfusion of the transplanted kidney and normal resistant index (0.61-0.68), with no evidence of vascular or urinary tract abnormality. Protocol biopsy was not performed. Graft function was stable with a tacrolimus trough level of approximately $10 \mathrm{ng} / \mathrm{mL}$.

At 3 months after KT, serum creatinine had increased to $1.56 \mathrm{mg} / \mathrm{dL}$, and blood tacrolimus trough level was 10.2 $\mathrm{ng} / \mathrm{mL}$. Following a reduction of tacrolimus dose, serum creatinine decreased to $1.40 \mathrm{mg} / \mathrm{dL}$. At 4.2 months, serum creatinine level had again increased to $1.60 \mathrm{mg} / \mathrm{dL}$ with a tacrolimus trough level of $4.8 \mathrm{ng} / \mathrm{mL}$. C-reactive protein level and urinalysis were both within normal range, however, protein/creatinine ratio was $0.25 \mathrm{~g} / \mathrm{gCr}$. ABO titer values were anti $A$ of $1: 16$ and anti-B of 1:1. To detect acute rejection, kidney biopsy was performed at this time, showing no evidence of acute rejection (Fig. 1). Serum creatinine decreased to $1.29 \mathrm{mg} / \mathrm{dL}$ without any further specific management.

However, at 18 months after $\mathrm{KT}$, the patient wanted to stop steroid treatment owing to fear of its long-term complications. Steroid tapering was initiated at 20 months after KT and accomplished at 26 months. The patient had maintained methylprednisolone at $4 \mathrm{mg} /$ day at the time of initiation of steroid tapering, followed by lowering of the dosage to $4 \mathrm{mg} \mathrm{q} 48$ hours for 6 months, after which steroid administration was terminated. At that point, serum creatinine level had decreased to $1.13 \mathrm{mg} / \mathrm{dL}$, and anti-A and anti-B isoagglutinin titers were $1: 8$ and $1: 2$, respectively.

No issues were observed after steroid withdrawal. Serum creatinine levels were 1.19 and $1.21 \mathrm{mg} / \mathrm{dL}$ at 36 and 48 months after KT, respectively (Table 1). Anti-A
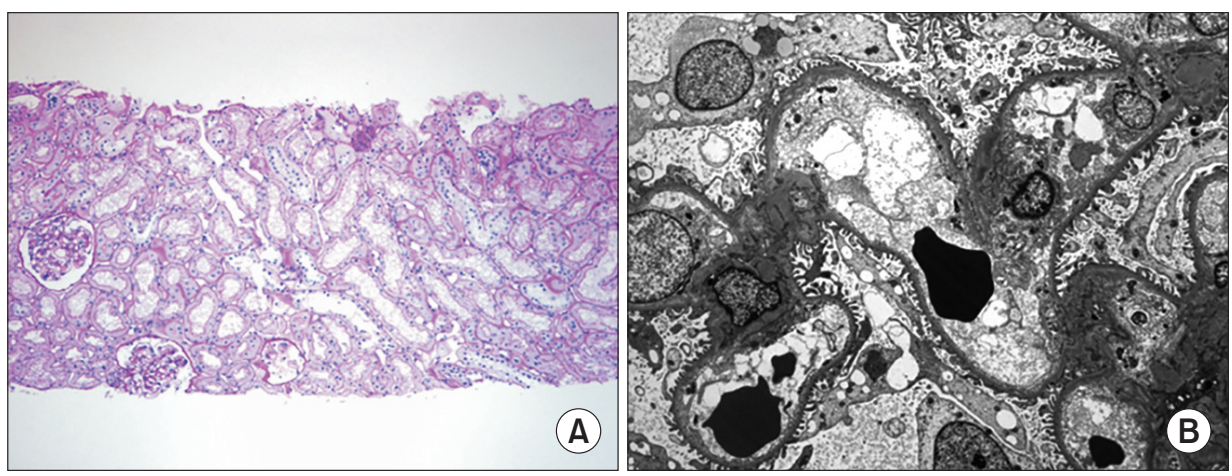

Fig. 1. Transplanted kidney biopsy. (A) Periodic Acid Schiff stain, $\times 100$. (B) Electron microscopy, $\times 2,500$. Kidney biopsy showed nonspecific changes. No electron dense deposits were noted in ultrastructural examination. The glomerular basement membrane was normal in thickness with smooth inner and outer contours. Epithelial foot processes were intact. No multilayering was noted in peritubular capillary basement membrane. 
Table 1. Laboratory findings of pre- and post-KT

\begin{tabular}{lccc}
\hline \multicolumn{1}{c}{ Variable } & Pre-KT & 20 Months & 48 \\
\hline Creatinine $(\mathrm{mg} / \mathrm{dL})$ & 7.82 & 1.13 & 1.21 \\
eGFR (CKD-EPI, mL/min/1.73 $\left.\mathrm{m}^{2}\right)$ & 7.7 & 78 & 71 \\
Blood urea nitrogen $(\mathrm{mg} / \mathrm{dL})$ & 59.4 & 12.8 & 12.4 \\
Hemoglobin $(\mathrm{g} / \mathrm{dL})$ & 10.4 & 15.9 & 14.9 \\
WBC $(/ \mathrm{uL})$ & 7,960 & 8,170 & 6,820 \\
Fasting blood glucose $(\mathrm{mg} / \mathrm{dL})$ & 85 & 87 & 98 \\
Uric acid $(\mathrm{mg} / \mathrm{dL})$ & 2.6 & 6.9 & 6.6 \\
TG $(\mathrm{mg} / \mathrm{dL})$ & 103 & NA & 102 \\
LDL $(\mathrm{mg} / \mathrm{dL})$ & 68 & NA & 101 \\
Urine protein/creatinine ratio & 0.36 & $<0.15$ & $<0.15$ \\
Anti-A titer & $1: 16$ & $1: 8$ & $1: 32$ \\
Anti-B titer & $1: 8$ & $1: 2$ & $1: 2$ \\
PRA & Negative & Negative & Negative \\
\hline
\end{tabular}

$\mathrm{KT}$, kidney transplantation; eGFR, estimated glomerular filtration rate; WBC, white blood cell; TG, triglyceride; NA: not available; LDL, low-density lipoprotein; PRA, panel-reactive antibody.

and anti-B antibody titers were $1: 32$ and $1: 2$ at 36 and 48 months after $\mathrm{KT}$, respectively. PRA remained negative at 12,24 , and 36 months after transplantation. Currently, the patient has been taking tacrolimus $0.75 \mathrm{mg}$ and enteric coated mycophenolic acid $540 \mathrm{mg}$ (both twice per day). The patient showed no evidence of any metabolic complications such as hypertension, diabetes or dyslipidemia.

\section{DISCUSSION}

The number of $\mathrm{ABO}-\mathrm{i} \mathrm{KT}$ procedures has been increasing annually worldwide [5]. In Korea, the number of ABO-i KT cases has increased by 2018 to account for $26.3 \%$ of all KT since it was first introduced in 2007. ABO-i KT is now a routine procedure with short- and long-term success rates comparable with those of ABO-c KT $[2,4,6]$. According to data from the Scientific Registry of Transplant Recipients between 1995 and 2010, 1-year graft survival rate was $94.1 \%$ in ABO-i KT versus $97.1 \%$ in ABO-c KT [5]. According to an $A B O-i K T$ series from Japan, 9-year graft survival in $A B O-i$ and $A B O-c$ patients were $59 \%$ and $57 \%$, respectively [7]. Although the rate of antibody-mediated rejection was higher in patients undergoing $\mathrm{ABO}-\mathrm{i} \mathrm{KT}$ than in those undergoing $\mathrm{ABO}-\mathrm{C} \mathrm{KT}$, the risk of $\mathrm{T}$ cell-mediated rejection was not different between the two groups [8].

Although there are fundamental drugs to avoid and treat graft rejection, adverse effects of glucocorticoid treatment are inevitable. Efforts to minimize steroid use in $\mathrm{KT}$ recipients can reduce steroid toxicity and achieve improved long-term outcomes. However, the results of ABO-C KT remain controversial [9-13]. Currently, early steroid withdrawal can be applied to patients with low immunologic risk and high metabolic complications and to those who have received lymphocyte-depleting therapy during $\mathrm{ABO}-\mathrm{C} \mathrm{KT}$.

Few data exist regarding early steroid withdrawal in ABO-i KT cases. One study demonstrated successful early steroid withdrawal in $44 \%$ of $\mathrm{ABO}-\mathrm{i} \mathrm{KT}$ patients and biopsy-proven acute rejection in 30\% [4]. In the previously mentioned study, basiliximab and high-dose methylprednisolone were administered as induction therapy, and methylprednisolone was stopped on day 14 after KT. Thereafter, maintenance immunosuppression regimen comprised cyclosporin and MMF. However, 50 of 130 patients resumed steroid treatment, particularly due to acute rejection and suspicion of rejection in 33 of the 50 patients. A small, uncontrolled, short term study of steroid withdrawal on day 7 in 10 patients after ABO-i KT reported graft survival of $100 \%$ and biopsy-proven acute rejection of $30 \%$. Maintenance immunosuppression regimen for this study comprised tacrolimus and MMF [3].

Some data exist regarding late steroid withdrawal 3 months after ABO-i KT. Oettl et al. [2] first reported the results of late steroid withdrawal. In their study, if protocol biopsy at 12-14 months posttransplantation showed no evidence of rejection, prednisone was tapered slowly and stopped after 8 to 12 weeks while maintaining tacrolimus and MMF. Graft survival in this study was $100 \%$ after a median follow-up of 839 days. Steroid withdrawal was successful in five of 11 patients; however, it failed in the remaining six patients owing to biopsy-proven acute rejection. This $55 \%$ rejection rate was relatively high compared with early steroid withdrawal $(30 \%-40 \%)$. Conversely, Novosel and Bistrup [1] reported optimistic results of steroid withdrawal. Their retrospective, single-center study showed successful steroid withdrawal in $86 \%$ of patients after 289 days and 1-year rejection rate of $19 \%$ without protocol biopsy. This provides clinical evidence that prednisolone can be safely tapered 3 months after $\mathrm{KT}$ without any increases in rejection rates, loss of graft function, or mortality.

The patient in the present report underwent late steroid withdrawal 26 months after KT, without kidney biopsy at the time of steroid withdrawal. The time at which 
he stopped steroid treatment at most 26 months later than other studies on steroid withdrawal. Even up to 48 months, graft function was well maintained without any issues of acute or chronic rejection. This positive outcome may have resulted from the patient being immunologically low-risk. ABO antibody titer is associated with increased rejection risk, in addition to traditional risk factors including high PRA, blood transfusion, retransplant and deceased donor grafts $[14,15]$. The patient's preoperative ABO antibody titer was low, and PRA was negative, and he underwent living donor KT from his sibling. Although steroid withdrawal after ABO-i KT is not recommended, it may be attempted in immunologically low risk patients with confirmation of biopsy-proven normal histological findings [6].

\section{ACKNOWLEDGMENTS}

\section{Conflict of Interest}

No potential conflict of interest relevant to this article was reported.

\section{Funding/Support}

This study was supported by research grant from the Korean Society for Transplantation (2020-02-02004-009).

\section{Previous Presentation}

This case was presented as a poster at the ATW 2019 (Gyeongju, Korea).

\section{ORCID}

Jeong Min Cho https://orcid.org/0000-0001-7643-994X Heungman Jun https://orcid.org/0000-0003-2530-4388 Hyung Ah Jo https://orcid.org/0000-0002-5574-554X Kum Hyun Han https://orcid.org/0000-0003-3700-0066 Han-Seong Kim https://orcid.org/0000-0003-3740-0588 Sang Youb Han https://orcid.org/0000-0003-3312-0597

\section{Author Contributions}

Conceptualization: JMC, SYH. Data curation: JMC, HJ. Formal analysis: JMC, HAJ. Methodology: JMC, KHH, Project administration: JMC, SYH. Visualization: JMC, HSK. Writing-original draft: JMC. Writing-review \& editing: $\mathrm{SYH}$.

\section{REFERENCES}

1. Novosel MK, Bistrup C. Discontinuation of steroids in ABO-incompatible renal transplantation. Transpl Int 2016;29:464-70.

2. Oettl T, Zuliani E, Gaspert A, Hopfer H, Dickenmann $\mathrm{M}$, Fehr T. Late steroid withdrawal after ABO blood group-incompatible living donor kidney transplantation: high rate of mild cellular rejection. Transplantation 2010;89:702-6.

3. Galliford J, Charif R, Chan KK, Loucaidou M, Cairns T, Cook HT, et al. ABO incompatible living renal transplantation with a steroid sparing protocol. Transplantation 2008;86:901-6.

4. Kato Y, Tojimbara T, Iwadoh K, Koyama I, Nanmoku K, Kai K, et al. Early steroid withdrawal protocol with basiliximab, cyclosporine and mycophenolate mofetil in renal-transplant recipients. Int Immunopharmacol 2006;6:1984-92.

5. Montgomery JR, Berger JC, Warren DS, James NT, Montgomery RA, Segev DL. Outcomes of ABO-incompatible kidney transplantation in the United States. Transplantation 2012;93:603-9.

6. Koo TY, Yang J. Current progress in ABO-incompatible kidney transplantation. Kidney Res Clin Pract 2015;34:170-9.

7. Takahashi K, Saito K, Takahara S, Okuyama A, Tanabe $\mathrm{K}$, Toma $\mathrm{H}$, et al. Excellent long-term outcome of ABO-incompatible living donor kidney transplantation in Japan. Am J Transplant 2004;4:1089-96.

8. Scurt FG, Ewert L, Mertens PR, Haller H, Schmidt BM, Chatzikyrkou C. Clinical outcomes after ABO-incompatible renal transplantation: a systematic review and meta-analysis. Lancet 2019;393:2059-72.

9. Woodle ES, First MR, Pirsch J, Shihab F, Gaber AO, Van Veldhuisen $P$, et al. A prospective, randomized, double-blind, placebo-controlled multicenter trial comparing early (7 day) corticosteroid cessation versus long-term, low-dose corticosteroid therapy. Ann Surg 2008;248:564-77.

10. Bae S, Garonzik Wang JM, Massie AB, Jackson KR, McAdams-DeMarco MA, Brennan DC, et al. Early steroid withdrawal in deceased-donor kidney transplant recipients with delayed graft function. J Am Soc Nephrol 2020;31:175-85.

11. Barbour S, Djurdjev O, Gill JS, Dong JJ, Gill J. A propensity score matched analysis shows no adverse effect of early steroid withdrawal in non-diabetic kidney 
transplant recipients with and without glomerulonephritis. Kidney Int 2019;96:460-9.

12. Haller MC, Royuela A, Nagler EV, Pascual J, Webster AC. Steroid avoidance or withdrawal for kidney transplant recipients. Cochrane Database Syst Rev 2016;(8):CD005632.

13. Taber DJ, Hunt KJ, Gebregziabher M, Srinivas T, Chavin $\mathrm{KD}$, Baliga PK, et al. A comparative effectiveness analysis of early steroid withdrawal in black kidney trans- plant recipients. Clin J Am Soc Nephrol 2017;12:131-9.

14. Tobian AA, Shirey RS, Montgomery RA, Cai W, Haas $M$, Ness $P M$, et al. $A B O$ antibody titer and risk of antibody-mediated rejection in $\mathrm{ABO}$-incompatible renal transplantation. Am J Transplant 2010;10:1247-53.

15. Chung BH, Lim JU, Kim Y, Kim JI, Moon IS, Choi BS, et al. Impact of the baseline anti-A/B antibody titer on the clinical outcome in $\mathrm{ABO}$-incompatible kidney transplantation. Nephron Clin Pract 2013;124:79-88. 